\title{
A Plausible Biological Mechanism by which Extremely Low-Frequency Electromagnetic Fields Increase the Risk of Childhood Leukemia
}

\author{
Miguel López-Lázaro \\ Department of Pharmacology, Faculty of Pharmacy, University of Seville, C/ Profesor Garcia Gonzalez 2, 41012 \\ Sevilla, Spain; mlopezlazaro@us.es; Tel: +34-954-55-63-48. Fax: +34-954-23-37-65
}

\begin{abstract}
Extremely low-frequency electromagnetic fields (ELF-EMFs) are non-ionizing radiations typically emitted by power lines, electrical wiring and electrical appliances. Epidemiological studies have repeatedly shown a positive association between ELF-EMFs and childhood leukemia. Exposures greater than $0.3-0.4 \mu \mathrm{T}$ increase the risk by approximately $1.5-2$ fold, and estimates indicate that up to $2 \%$ of childhood leukemia cases in Europe may be attributable to ELF-EMFs. However, it is considered unlikely that ELF-EMFs can cause cancer, because carcinogenesis requires the accumulation of DNA alterations and ELF-EMFs do not have enough energy to damage the DNA. Lack of biological plausibility is a barrier to accept the evidence of carcinogenicity in human studies and to take measures to protect pregnant women and children from ELF-EMFs. Recent evidence indicates that non-mutagenic agents can cause DNA alterations and increase the risk of cancer by promoting the accumulation of cell divisions in stem cells. Cell division generates DNA alterations (e.g., mutations arising during DNA replication), which occur even in the absence of DNA-damaging agents. Importantly, ELF-EMFs can trigger the division of stem cells; this effect is under development in the field of regenerative medicine. A possible mechanism by which ELF-EMFs induce the malignant transformation of hematopoietic stem cells is discussed.
\end{abstract}

Keywords: magnetic fields; power lines; cancer; carcinogenesis; stem cell division theory of cancer

\section{Introduction: Basic concepts on ELF-EMFs}

Extremely low frequency electromagnetic fields (ELF-EMFs) are non-ionizing radiations with a frequency range between 0 and 3000 cycles per second or hertz (Hz). ELF-EMFs are associated with the distribution and use of electricity (most electric power operates at a frequency of $50 \mathrm{or} 60 \mathrm{~Hz}$ ), and they are typically emitted by power lines, electrical wiring and electrical appliances. Unlike other EMFs of higher frequencies, the ELF electric and magnetic fields are not necessarily coupled and can be measured individually. Electric fields are areas of energy produced by the presence of an electric charge. These fields exist even when there is no electric current flowing, e.g., surrounding the cable of an appliance that is plugged in and switch off. Magnetic fields are areas of energy created when electric current flows; they are present around power lines and cables of switched-on appliances, coexisting with electric fields. The strength of an electric field is measured in volts per meter $(\mathrm{V} / \mathrm{m})$. The magnetic field strength is measured in amperes per meter $(\mathrm{A} / \mathrm{m})$, although it is more commonly expressed in tesla $(\mathrm{T})$, millitesla $(\mathrm{mT})$ or microtesla $(\mu \mathrm{T})$. Both electric and magnetic fields are strongest close to their origin and their strength markedly decreases at greater distances from the source. For example, the magnetic field strength of hair dryers is 6-2000 $\mu \mathrm{T}$ at a distance of $3 \mathrm{~cm}$, but decreases to $0.01-7 \mu \mathrm{T}$ at a distance of $30 \mathrm{~cm}$. Magnetic fields underneath power lines are about $20 \mu \mathrm{T}$. Electric fields are blocked by common materials such as the walls of buildings. However, magnetic fields are not shielded by most common materials and pass easily through them. ELF electric and magnetic fields do not have enough energy to ionize molecules and to cause DNA damage, but both have sufficient energy to induce the generation of electric currents within tissues $[1,2]$. 


\section{ELF-EMFs and childhood leukemia: Evidence of carcinogenicity in human studies}

In 1979, the first association between residential exposure to ELF-EMFs and childhood leukemia was observed [3]. Numerous studies, reviews and pooled analyses have been published since then. Two pooled analysis published in 2000 showed a positive association between ELF-EMFs and childhood leukemia. One of them included nine well conducted studies and reported a twofold increase in risk of childhood leukemia among children with exposures of $0.4 \mu \mathrm{T}$ or higher (RR: $2.0 ; 95 \% \mathrm{CI}: 1.27-3.13 ; P$ value: 0.002) [4]. Adjustment for potential confounding variables did not appreciably change the results. The authors concluded that the $99.2 \%$ of children residing in homes with exposure levels below $0.4 \mu \mathrm{T}$ had estimates compatible with no increased risk, while the $0.8 \%$ of children with exposures of $0.4 \mu \mathrm{T}$ or higher had a relative risk estimate of approximately two [4]. The other pooled analysis, which included 15 studies based on less restrictive inclusion criteria, showed a relative risk of 1.7 for exposure above $0.3 \mu \mathrm{T}$ [5]. Latter, a pooled analysis of seven studies published after 2000 reported a 1.4-fold increase in childhood leukemia among children with exposures of $0.3 \mu \mathrm{T}$ or higher [6]. New studies are in line with these large pooled analyses, typically showing relative risks between 1.5 and 2 [7-10]. For example, in a meta-analysis based on 11,699 cases and 13,194 controls, the relative risk was 1.57 for exposure above $0.4 \mu \mathrm{T}[10]$. Although most studies have been focused on exposure to EMFs emitted by power lines, several investigations have also evaluated the cancer risk associated with the use of electrical appliances. Several case-control studies have reported similar positive associations between childhood leukemia and use of electrical appliances (e.g., electric blankets) during pregnancy and childhood [11-14].

It has recently been estimated that up to $2 \%$ of childhood leukemia cases in Europe may be attributable to ELF-EMFs [15]. These estimates have been confirmed by researchers of the ARIMMORA (Advanced Research on Interaction Mechanisms of electroMagnetic exposures with Organisms for Risk Assessment) consortium [16]. Despite the evidence of carcinogenicity shown by numerous human studies, ELF-EMFs are not considered to be carcinogenic. Currently, guidelines for limiting exposure to ELF-EMFs are far above the levels found to increase the risk of childhood leukemia in epidemiological studies; the guideline limit for the general public is $100 \mu \mathrm{T}$ at $50 \mathrm{~Hz}$ and $83 \mu \mathrm{T}$ at $60 \mathrm{~Hz}$ [2]. Although children are particularly vulnerable to EMFs [17], this guideline limit is the same for adults and children.

\section{Lack of a plausible biological mechanism is an obstacle to classify ELF-EMFs as carcinogenic to humans}

The prevailing model of carcinogenesis, often called the somatic mutation theory, states that cancer is caused by mutations in oncogenes and tumor-suppressor genes. Mutations in oncogenes activate cell proliferation, whereas mutations in tumor-suppressor genes inhibit cell death or cell-cycle arrest. The multi-step accumulation of mutations in these genes causes the uncontrolled cell proliferation that characterizes the disease [18-21]. Because ELF-EMFs do not have enough energy to cause mutations, it is considered unlikely that exposure to ELF-EMFs can increase the risk of cancer. For example, a web page of the National Cancer Institute (USA) affirms that power lines do not cause cancer because the magnetic energy emitted by power lines is a low-frequency form of radiation that does not damage genes [22].

The International Agency for Research on Cancer (IARC), the cancer Agency of the World Health Organization, has an important role in the identification of human carcinogens. When IARC classifies an agent as carcinogenic to humans, national health agencies usually take measures to protect populations from the carcinogen. Despite the accumulation of human evidence indicating a positive association between exposure to ELF-EMFs and childhood leukemia, IARC does not consider ELF-EMFs to be carcinogenic to humans. The Agency considers that there is limited evidence in human studies, inadequate evidence in animal studies, and a lack of relevant mechanistic data [1].

IARC classifies an agent as carcinogenic to humans when there is sufficient evidence of carcinogenicity in human studies. According to the IARC's statement of scientific principles described in its Preamble [23], sufficient evidence of carcinogenicity means that "The Working Group considers that a 
causal relationship has been established between exposure to the agent and human cancer. That is, a positive relationship has been observed between the exposure and cancer in studies in which chance, bias and confounding could be ruled out with reasonable confidence." According to IARC, the lack of a relevant mechanism of carcinogenesis is not a determining factor when there is sufficient evidence of carcinogenicity in humans. If there is sufficient evidence in human studies, animal and mechanistic evidence is accessory [23]. This principle makes sense, because animals and humans do not always respond equally to all agents, and because not understanding how an agent can cause cancer should not be a barrier to take measures to protect people exposed to the agent. However, because the scientific criteria to determine whether or not there is sufficient evidence of carcinogenicity in human studies are not clearly defined (see Preamble [23]), the existence or lack of a plausible mechanism of carcinogenesis may be a motivation or an obstacle to classify an agent as carcinogenic to humans. For example, in their Monograph entitled "Chemical Agents and Related Occupations" (Volume 100F), IARC concludes that "There is sufficient evidence in humans for the carcinogenicity of 4-aminobiphenyl. 4-Aminobiphenyl causes bladder cancer in humans" [24]. However, the evidence in humans for the carcinogenicity of 4aminobiphenyl seems to be weaker than for ELF-EMFs. The evidence basically consists of several lowquality studies in a low number of workers at chemical plants, who were probably exposed to other chemicals [24]. It is possible that the evidence of carcinogenicity in humans was considered sufficient because there was strong mechanistic evidence indicating that the carcinogenicity of 4-aminobiphenyl operates by a known genotoxic mechanism. This paragraph is not to say that 4-aminobiphenyl is not carcinogenic to humans; the whole evidence strongly suggests that it is. It is to say that the lack of a plausible mechanism may be an obstacle to classify ELF-EMFs as carcinogenic to humans and, therefore, to take measures to protect children and pregnant women from ELF-EMFs.

\section{The stem cell division theory of cancer provides a new framework to explain the carcinogenicity of non-mutagenic agents}

The stem cell division theory of cancer was initially proposed in a short editorial [25] and has been extended and explained in more detail in a recent working paper [26]. It can be summed up in one sentence: the main biological cause of cancer is the accumulation of cell divisions in stem cells; the more cell divisions a stem cell accumulates from the zygote until it dies or loses its ability to divide, the higher the probability that the stem cell will divide uncontrollably to form a cancer. In other words, the main determinant of carcinogenesis is the number of cell divisions that the DNA of a functional stem cell has gone thorough from the zygote. This model of carcinogenesis is based on the striking differences in cancer risk by age and among tissues. Observational studies based on millions and millions of people around the world are continually showing that cancer incidence increases dramatically with age. These studies are also continuously showing striking differences in cancer incidence among tissues; cancer arises even a million times more often in tissues with a high self-renewal capacity than in tissues without this capacity. The stem cell division model can explain these striking differences in cancer incidence [2529]. For example, prostate cancer is over 2,800 times more frequently diagnosed in men over 60 years old than in men under 30 [30] because the stem cells involved in the formation and maintenance of the prostate accumulate cell divisions with age [25-27]. Colon cancer is about 100,000 times more common than heart cancer [30-32] because the stem cells involved in the formation and maintenance of the colon accumulate many more cell divisions than those involved in the formation and maintenance of the heart [25-27]. Every time a cell divides, it becomes exposed to unavoidable mistakes associated with cell division, including mutations arising during DNA replication, chromosome aberrations occurring during mitosis, and failures in the distribution of cellular components between the daughter cells (e.g., cellular components that determine cell fate). Dividing cells are also highly vulnerable to endogenous and exogenous DNA-damaging agents (e.g., reactive oxygen species and tobacco carcinogens). The accumulation of cell divisions in stem cells drives the accumulation of the DNA alterations required for carcinogenesis [26].

This model of carcinogenesis implies that the risk of developing cancer is not only increased by mutagenic agents, but by any factor that promotes the accumulation of cell divisions in stem cells (Figure 
1). Promoting the division of stem cells will result in DNA alterations associated with cell divisions (e.g., mutations arising during DNA replication), which will occur even in the absence of DNA-damaging agents $[25,26]$. For example, the stem cell division model explains why drinking very hot beverages increases the risk of developing esophageal cancer [33-36]. When we drink (or eat) something hot enough to cause severe damage to the cells lining the esophagus, the stem cells located in deeper layers of the mucosa have to divide to produce new cells to replace the damaged cells. When stem cells divide to regenerate the epithelium, their DNA becomes exposed to unavoidable errors associated with cell division and also becomes highly vulnerable to endogenous and exogenous genotoxic agents. The more stem cell divisions, the more DNA alterations and, therefore, the higher the risk of cancer. Any mutagenic or nonmutagenic factor that promotes the accumulation of cell divisions in stem cells will increase the risk of cancer $[26,33]$.

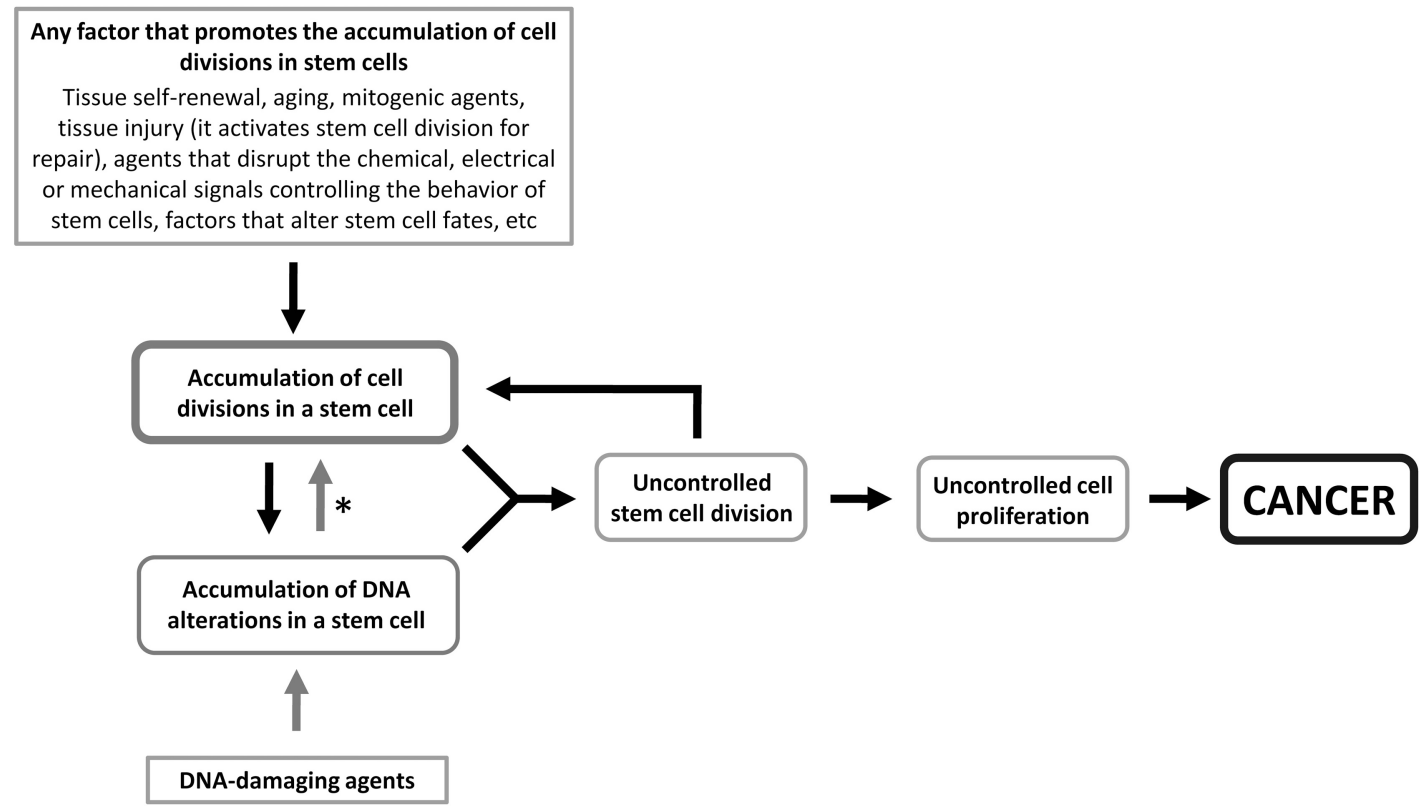

Figure 1. Stem cell division theory of cancer. This theory proposes that the main biological cause of cancer is the accumulation of cell divisions in stem cells; the more cell divisions a stem cell accumulates from the zygote until it dies or loses its ability to divide, the higher the probability that the stem cell will divide uncontrollably to form a cancer. In other words, the main determinant of carcinogenesis is the number of cell divisions that the DNA of a functional stem cell has gone thorough from the zygote. At the initial stages of carcinogenesis, the accumulation of DNA alterations is a consequence of the accumulation of cell divisions rather than a cause, but the pathway becomes reversible $\left(^{*}\right)$ at the final stages of carcinogenesis. After accumulating enough cell divisions and DNA alterations, the stem cell can divide without control. This uncontrolled stem cell leads to the uncontrolled cell proliferation that characterizes cancer. The risk of developing cancer is not only increased by exposure to DNA-damaging agents, but by any factor that promotes the accumulation of cell divisions in stem cells. See text and reference [26] for details.

\section{ELF-EMFs may increase the risk of childhood leukemia by promoting the accumulation of cell divisions in hematopoietic stem cells}

Numerous investigations have shown that ELF-EMFs can stimulate the division of stem cells [3741]. It is well established that exposure to ELF-EMFs results in induction of electric fields and associated currents in tissues, an effect that has been used to promote tissue regeneration $[1,42,43]$. For example, several clinical studies have shown that magnetic fields are effective in stimulating bone healing; magnetic fields induce the generation of electric currents within the bone tissue, which enhance the activity of bone-forming cells. This effect has been observed with relatively weak magnetic fields $(\mu \mathrm{T}$ 
and $\mathrm{mT})[1,44]$. Since the division of stem cells is crucial for tissue regeneration, it is not surprising that ELF-EMFs can stimulate the division of stem cells of a variety of tissues [37-41].

The mechanisms by which ELF-EMFs stimulate the division of stem cells in vivo are largely unknown, probably because the physiological mechanisms controlling stem cell behavior are poorly understood. Although ELF-EMFs can induce a direct mitogenic effect on stem cells [37-41], they may also activate their division by acting on extracellular factors. The division of stem cells is highly regulated by a variety of local, systemic and environmental signals. For example, their division rates are regulated by mechanical and electric interactions with the cellular and non-cellular components forming their anatomical location. The division of stem cells is also regulated by local and systemic chemical mediators (e.g., hormones, growth factors and cytokines), and by a variety of signals generated inside and outside the body that the nervous system receives and converts into chemical and physical messages controlling their division rates [26,45-47].

ELF-EMFs may also promote the accumulation of cell divisions in stem cells by disrupting stem cell fates (i.e., quiescence, self-renewal, differentiation, migration and survival) [26]. For example, any nonmitogenic stimulus that prevents the programmed cell death or symmetric differentiation of a stem cell will promote the accumulation of cell divisions in the stem cell. Any factor inducing or altering the migration of a stem cell may also facilitate the accumulation of cell divisions if the cell reaches an abnormal location that imposes high cell division rates [26]. Evidence indicates that cell migration is highly influenced by physiological electric currents [48-51], and ELF-EMFs can induce electric currents and alter cell migration [1,42,43,52-54]. ELF-EMFs may therefore disrupt the migration of stem cells. This disrupting effect does not necessarily have to increase with cumulative doses of electromagnetic radiation. A peak of ELF-EMFs may be sufficient to alter the migration and fate of a stem cell. This would explain why some studies provide no discernable pattern of increased cancer risk associated with increased duration and frequency of exposure to ELF-EMFs.

Evidence strongly suggests that leukemia arises from hematopoietic stem cells (HSCs) [55-59]. In addition, HSCs are known to migrate during embryonic development and early childhood [60]; this allows different sites to participate in hematopoiesis at different moments in life. The liver is the primary hematopoietic organ during fetal development, whereas the bone marrow becomes the main hematopoietic site after birth. In children, hematopoiesis occurs in the marrow of the long bones (e.g., femur and tibia), whereas the marrow of other bones (e.g., pelvis, vertebrae and sternum) is responsible for hematopoiesis in adults [60,61]. Since cell migration is regulated by physiological electric currents [48-51] and ELF-EMFs can induce electric currents and alter cell migration [1,42,43,52-54], it is possible that ELF-EMFs can disrupt the migration HSCs.

Because the anatomical location of HSCs and the signals controlling their division and migration vary during embryonic development, childhood and adulthood [60], the carcinogenic activity of ELFEMFs may differ at different moments in life. This would explain why exposure to ELF-EMFs increases the risk of leukemia in children but not in adults. Accordingly, although carcinogenicity experiments in rodents have been largely negative [62], recent experiments have shown an increased risk of leukemia in rodents exposed to ELF-EMFs from prenatal life [63,64]. Evidence or lack of carcinogenicity in rodents exposed to ELF-EMFs should however be interpreted cautiously, because rodents and humans may not respond equally to non-ionizing electromagnetic radiation.

Non-DNA-damaging carcinogens increase the risk of cancer by promoting the accumulation of cell divisions in stem cells; the accumulation of cell divisions in stem cells results in the accumulation of the DNA alterations required for carcinogenesis (Figure 1). Because ELF-EMFs do not have sufficient energy to cause DNA damage, they probably increase the risk of childhood leukemia by promoting the accumulation of cell divisions in HSCs. ELF-EMFs may induce the accumulation of cell divisions in HSCs by inducing a direct mitogenic effect, by altering extracellular signals controlling their division rates, or by modifying stem cell fates (i.e., quiescence, self-renewal, differentiation, migration and survival). They may do so by disrupting electrical signals controlling the behavior of HSCs. Experimentally demonstrating that ELF-EMFs increase the risk of childhood leukemia by promoting the 
accumulation of cell divisions in human HSCs in vivo is difficult and probably unethical. However, evidence suggests that this biological mechanism is plausible enough to admit that the carcinogenicity of ELF-EMFs observed in human studies is not an epidemiological artifact caused by bias, confounding or chance.

\title{
6. Conclusion
}

Human studies have repeatedly shown that exposure to ELF-EMFs increase the risk of childhood leukemia. Exposures greater than 0.3-0.4 $\mu \mathrm{T}$ increase the risk by approximately 1.5-2 fold, and estimates indicate that up to $2 \%$ of childhood leukemia cases in Europe may be attributable to ELF-EMFs. However, because carcinogenesis requires the accumulation of DNA alterations and non-ionizing EMFs do not have sufficient energy to cause DNA damage, it is considered unlikely that exposure to ELF-EMFs can cause cancer. Currently, ELF-EMFs are not considered to be carcinogenic to humans, and the guidelines for limiting exposure to ELF-EMFs $(100 \mu \mathrm{T}$ at $50 \mathrm{~Hz})$ are far above the levels found to increase the risk of childhood leukemia in human studies. Not having a biological explanation for the epidemiological link between ELF-EMFs and childhood leukemia is a barrier to classify ELF-EMFs as carcinogenic to humans and, therefore, to develop guidelines to protect children and pregnant women from ELF-EMFs. Recent evidence indicates that non-mutagenic agents can increase the risk of cancer by promoting the accumulation of cell divisions in stem cells. Cell division is associated with unavoidable DNA alterations (e.g., mutations arising during DNA replication) that occur even in the absence of DNAdamaging agents. Data discussed in this manuscript indicate that ELF-EMFs may increase the risk of childhood leukemia by promoting the accumulation of cell divisions in HSCs. The accumulation of cell divisions in HSCs would promote the accumulation of the DNA alterations required for their malignant transformation. Biological plausibility should not be raised as an objection to accept that exposure to ELF-EMFs increases the risk of childhood leukemia. Health protection agencies should develop policies to protect pregnant women and children from ELF-EMFs. This call for protection from non-ionizing EMFs is shared by many scientists from over 40 nations [65].

Conflicts of Interest: The author declares no conflict of interest.

\author{
Abbreviations \\ ELF-EMFs: extremely low-frequency electromagnetic fields \\ EMFs: electromagnetic fields \\ IARC: International Agency for Research on Cancer \\ HSCs: hematopoietic stem cells
}

\section{References}

1. International Agency for Research on Cancer. IARC Monographs on the Evaluation of Carcinogenic Risks to Humans. Volume 80: Non-Ionizing Radiation, Part 1: Static and Extremely Low-Frequency (ELF) Electric and Magnetic Fields. 2002. Available online: http://monographs.iarc.fr/ENG/Monographs/vol80/index.php (accessed on August 15, 2016).

2. Electromagnetic fields (EMF). Available online: http://www.who.int/peh-emf/en/ (accessed on 15 August 2016).

3. Wertheimer, N.; Leeper, E. Electrical wiring configurations and childhood cancer. Am J Epidemiol 1979, 109, 273-284.

4. Ahlbom, A.; Day, N.; Feychting, M.; Roman, E.; Skinner, J.; Dockerty, J.; Linet, M.; McBride, M.; Michaelis, J.; Olsen, J.H.; Tynes, T.; Verkasalo, P.K. A pooled analysis of magnetic fields and childhood leukaemia. $\mathrm{Br} J$ Cancer 2000, 83, 692-698. 
5. Greenland, S.; Sheppard, A.R.; Kaune, W.T.; Poole, C.; Kelsh, M.A. A pooled analysis of magnetic fields, wire codes, and childhood leukemia. Childhood Leukemia-EMF Study Group. Epidemiology 2000, 11, 624-634.

6. Kheifets, L.; Ahlbom, A.; Crespi, C.M.; Draper, G.; Hagihara, J.; Lowenthal, R.M.; Mezei, G.; Oksuzyan, S.; Schuz, J.; Swanson, J.; Tittarelli, A.; Vinceti, M.; Wunsch, F., V. Pooled analysis of recent studies on magnetic fields and childhood leukaemia. Br J Cancer 2010, 103, 1128-1135.

7. Pedersen, C.; Johansen, C.; Schuz, J.; Olsen, J.H.; Raaschou-Nielsen, O. Residential exposure to extremely lowfrequency magnetic fields and risk of childhood leukaemia, CNS tumour and lymphoma in Denmark. $\mathrm{Br} J$ Cancer 2015, 113, 1370-1374.

8. Crespi, C.M.; Vergara, X.P.; Hooper, C.; Oksuzyan, S.; Wu, S.; Cockburn, M.; Kheifets, L. Childhood leukaemia and distance from power lines in California: a population-based case-control study. Br J Cancer 2016, 115, 122128.

9. Schuz, J. Exposure to extremely low-frequency magnetic fields and the risk of childhood cancer: update of the epidemiological evidence. Prog Biophys Mol Biol 2011, 107, 339-342.

10. Zhao, L.; Liu, X.; Wang, C.; Yan, K.; Lin, X.; Li, S.; Bao, H.; Liu, X. Magnetic fields exposure and childhood leukemia risk: a meta-analysis based on 11,699 cases and 13,194 controls. Leuk Res 2014, 38, 269-274.

11. Hatch, E.E.; Linet, M.S.; Kleinerman, R.A.; Tarone, R.E.; Severson, R.K.; Hartsock, C.T.; Haines, C.; Kaune, W.T.; Friedman, D.; Robison, L.L.; Wacholder, S. Association between childhood acute lymphoblastic leukemia and use of electrical appliances during pregnancy and childhood. Epidemiology 1998, 9, 234-245.

12. Savitz, D.A.; John, E.M.; Kleckner, R.C. Magnetic field exposure from electric appliances and childhood cancer. Am J Epidemiol 1990, 131, 763-773.

13. London, S.J.; Thomas, D.C.; Bowman, J.D.; Sobel, E.; Cheng, T.C.; Peters, J.M. Exposure to residential electric and magnetic fields and risk of childhood leukemia. Am J Epidemiol 1991, 134, 923-937.

14. Dockerty, J.D.; Elwood, J.M.; Skegg, D.C.; Herbison, G.P. Electromagnetic field exposures and childhood cancers in New Zealand. Cancer Causes Control 1998, 9, 299-309.

15. Grellier, J.; Ravazzani, P.; Cardis, E. Potential health impacts of residential exposures to extremely low frequency magnetic fields in Europe. Environ Int 2014, 62, 55-63.

16. Schuz, J.; Dasenbrock, C.; Ravazzani, P.; Roosli, M.; Schar, P.; Bounds, P.L.; Erdmann, F.; Borkhardt, A.; Cobaleda, C.; Fedrowitz, M.; Hamnerius, Y.; Sanchez-Garcia, I.; Seger, R.; Schmiegelow, K.; Ziegelberger, G.; Capstick, M.; Manser, M.; Muller, M.; Schmid, C.D.; Schurmann, D.; Struchen, B.; Kuster, N. Extremely lowfrequency magnetic fields and risk of childhood leukemia: A risk assessment by the ARIMMORA consortium. Bioelectromagnetics 2016, 10. doi: 10.1002/bem.21963

17. Kheifets, L.; Repacholi, M.; Saunders, R.; van Deventer, E. The sensitivity of children to electromagnetic fields. Pediatrics 2005, 116, e303.

18. Vogelstein, B.; Kinzler, K.W. Cancer genes and the pathways they control. Nat Med 2004, 10, 789-799.

19. Vogelstein, B.; Kinzler, K.W. The Path to Cancer --Three Strikes and You're Out. N Engl J Med 2015, 373, 1895 1898.

20. Tomasetti, C.; Marchionni, L.; Nowak, M.A.; Parmigiani, G.; Vogelstein, B. Only three driver gene mutations are required for the development of lung and colorectal cancers. Proc Natl Acad Sci U S A 2015, 112, 118-123.

21. Vaux, D.L. In defense of the somatic mutation theory of cancer. Bioessays 2011, 33, 341-343.

22. Common Cancer Myths and Misconceptions. Available online: http://www.cancer.gov/about-cancer/causesprevention/risk/myths (accessed on August 13, 2016).

23. Preamble to the IARC Monographs. Available online: http://monographs.iarc.fr/ENG/Preamble/index.php (accessed on August 15, 2016).

24. International Agency for Research on Cancer. IARC Monographs on the Evaluation of Carcinogenic Risks to Humans. Volume 100F: Chemical Agents and Related Occupations. 2012. Available online: http://monographs.iarc.fr/ENG/Monographs/vol100F/index.php (accessed on August 15, 2016).

25. Lopez-Lazaro, M. Stem cell division theory of cancer. Cell Cycle 2015, 14, 2547-2548. 
26. Lopez-Lazaro, M. Understanding cancer: 15 questions and answers. ResearchGate, 2016, DOI: 10.13140/RG.2.1.4180.6323, http://dx.doi.org/10.13140/RG.2.1.4180.6323.

27. Lopez-Lazaro, M. Cancer arises from stem cells: opportunities for anticancer drug discovery. Drug Discov Today 2015, 20, 1285-1287.

28. Lopez-Lazaro, M. What Is the Main Cause of Cancer? Preprints 2016, 2016080130, doi: 10.20944/preprints201608.0130.v1

29. Lopez-Lazaro, M. A local mechanism by which alcohol consumption causes cancer. Preprints 20162016080158 , doi:10.20944/preprints201608.0158.v1

30. SEER Cancer Statistis Review, 1975-2012. 2015, http://seer.cancer.gov/archive/csr/1975_2012/results_merged/topic_lifetime_risk.pdf

31. Tomasetti, C.; Vogelstein, B. Cancer etiology. Variation in cancer risk among tissues can be explained by the number of stem cell divisions. Science 2015, 347, 78-81.

32. Oliveira, G.H.; Al Kindi, S.G.; Hoimes, C.; Park, S.J. Characteristics and Survival of Malignant Cardiac Tumors: A 40-Year Analysis of $>500$ Patients. Circulation 2015, 132, 2395-2402.

33. Lopez-Lazaro, M. Understanding why aspirin prevents cancer and why consuming very hot beverages and foods increases esophageal cancer risk. Controlling the division rates of stem cells is an important strategy to prevent cancer. Oncoscience 2015, 2, 849-856.

34. Loomis, D.; Guyton, K.Z.; Grosse, Y.; Lauby-Secretan, B.; El Ghissassi, F.; Bouvard, V.; Benbrahim-Tallaa, L.; Guha, N.; Mattock, H.; Straif, K. Carcinogenicity of drinking coffee, mate, and very hot beverages. Lancet Oncol 2016, 17, 877-878.

35. Islami, F.; Pourshams, A.; Nasrollahzadeh, D.; Kamangar, F.; Fahimi, S.; Shakeri, R.; Abedi-Ardekani, B.; Merat, S.; Vahedi, H.; Semnani, S.; Abnet, C.C.; Brennan, P.; Moller, H.; Saidi, F.; Dawsey, S.M.; Malekzadeh, R.; Boffetta, P. Tea drinking habits and oesophageal cancer in a high risk area in northern Iran: population based case-control study. BMJ 2009, 338:b929.

36. Islami, F.; Boffetta, P.; Ren, J.S.; Pedoeim, L.; Khatib, D.; Kamangar, F. High-temperature beverages and foods and esophageal cancer risk--a systematic review. Int J Cancer 2009, 125, 491-524.

37. Ross, C.L.; Siriwardane, M.; Almeida-Porada, G.; Porada, C.D.; Brink, P.; Christ, G.J.; Harrison, B.S. The effect of low-frequency electromagnetic field on human bone marrow stem/progenitor cell differentiation. Stem Cell Res 2015, 15, 96-108.

38. Leone, L.; Podda, M.V.; Grassi, C. Impact of electromagnetic fields on stem cells: common mechanisms at the crossroad between adult neurogenesis and osteogenesis. Front Cell Neurosci 2015, 9:228. doi: 10.3389/fncel.2015.00228.

39. Maziarz, A.; Kocan, B.; Bester, M.; Budzik, S.; Cholewa, M.; Ochiya, T.; Banas, A. How electromagnetic fields can influence adult stem cells: positive and negative impacts. Stem Cell Res Ther 2016, 7, 54-0312.

40. Saliev, T.; Mustapova, Z.; Kulsharova, G.; Bulanin, D.; Mikhalovsky, S. Therapeutic potential of electromagnetic fields for tissue engineering and wound healing. Cell Prolif 2014, 47, 485-493.

41. Fan, W.; Qian, F.; Ma, Q.; Zhang, P.; Chen, T.; Chen, C.; Zhang, Y.; Deng, P.; Zhou, Z.; Yu, Z. 50 Hz electromagnetic field exposure promotes proliferation and cytokine production of bone marrow mesenchymal stem cells. Int J Clin Exp Med 2015, 8, 7394-7404.

42. Adey, W.R. Tissue interactions with nonionizing electromagnetic fields. Physiol Rev 1981, 61, 435-514.

43. Levin, M. Bioelectromagnetics in morphogenesis. Bioelectromagnetics 2003, 24, 295-315.

44. Cane, V.; Botti, P.; Soana, S. Pulsed magnetic fields improve osteoblast activity during the repair of an experimental osseous defect. J Orthop Res 1993, 11, 664-670.

45. Scadden, D.T. The stem-cell niche as an entity of action. Nature 2006, 441, 1075-1079.

46. Watt, F.M.; Huck, W.T. Role of the extracellular matrix in regulating stem cell fate. Nat Rev Mol Cell Biol 2013, 14, 467-473.

47. Sun, Y.; Chen, C.S.; Fu, J. Forcing stem cells to behave: a biophysical perspective of the cellular microenvironment. Annu Rev Biophys 2012, 41, 519-542. 
48. Levin, M. Molecular bioelectricity: how endogenous voltage potentials control cell behavior and instruct pattern regulation in vivo. Mol Biol Cell 2014, 25, 3835-3850.

49. Zhao, M.; Song, B.; Pu, J.; Wada, T.; Reid, B.; Tai, G.; Wang, F.; Guo, A.; Walczysko, P.; Gu, Y.; Sasaki, T.; Suzuki, A.; Forrester, J.V.; Bourne, H.R.; Devreotes, P.N.; McCaig, C.D.; Penninger, J.M. Electrical signals control wound healing through phosphatidylinositol-3-OH kinase-gamma and PTEN. Nature 2006, 442, 457-460.

50. Zhao, M. Electrical fields in wound healing-An overriding signal that directs cell migration. Semin Cell Dev Biol 2009, 20, 674-682.

51. McCaig, C.D.; Song, B.; Rajnicek, A.M. Electrical dimensions in cell science. J Cell Sci 2009, 122, 4267-4276.

52. Huo, R.; Ma, Q.; Wu, J.J.; Chin-Nuke, K.; Jing, Y.; Chen, J.; Miyar, M.E.; Davis, S.C.; Li, J. Noninvasive electromagnetic fields on keratinocyte growth and migration. J Surg Res 2010, 162, 299-307.

53. Iorio, R.; Bennato, F.; Mancini, F.; Colonna, R.C. ELF-MF transiently increases skeletal myoblast migration: possible role of calpain system. Int J Radiat Biol 2013, 89, 548-561.

54. Santini, M.T.; Rainaldi, G.; Indovina, P.L. Cellular effects of extremely low frequency (ELF) electromagnetic fields. Int J Radiat Biol 2009, 85, 294-313.

55. Bonnet, D.; Dick, J.E. Human acute myeloid leukemia is organized as a hierarchy that originates from a primitive hematopoietic cell. Nat Med 1997, 3, 730-737.

56. Hope, K.J.; Jin, L.; Dick, J.E. Acute myeloid leukemia originates from a hierarchy of leukemic stem cell classes that differ in self-renewal capacity. Nat Immunol 2004, 5, 738-743.

57. Reya, T.; Morrison, S.J.; Clarke, M.F.; Weissman, I.L. Stem cells, cancer, and cancer stem cells. Nature 2001, 414, 105-111.

58. Huntly, B.J.; Gilliland, D.G. Leukaemia stem cells and the evolution of cancer-stem-cell research. Nat Rev Cancer 2005, 5, 311-321.

59. Corces-Zimmerman, M.R.; Majeti, R. Pre-leukemic evolution of hematopoietic stem cells: the importance of early mutations in leukemogenesis. Leukemia 2014, 28, 2276-2282.

60. Mikkola, H.K.; Orkin, S.H. The journey of developing hematopoietic stem cells. Development 2006, 133, 37333744 .

61. Fernandez, K.S.; de Alarcon, P.A. Development of the hematopoietic system and disorders of hematopoiesis that present during infancy and early childhood. Pediatr Clin North Am 2013, 60, 1273-1289.

62. Brain, J.D.; Kavet, R.; McCormick, D.L.; Poole, C.; Silverman, L.B.; Smith, T.J.; Valberg, P.A.; Van Etten, R.A.; Weaver, J.C. Childhood leukemia: electric and magnetic fields as possible risk factors. Environ Health Perspect 2003, 111, 962-970.

63. Qi, G.; Zuo, X.; Zhou, L.; Aoki, E.; Okamula, A.; Watanebe, M.; Wang, H.; Wu, Q.; Lu, H.; Tuncel, H.; Watanabe, H.; Zeng, S.; Shimamoto, F. Effects of extremely low-frequency electromagnetic fields (ELF-EMF) exposure on B6C3F1 mice. Environ Health Prev Med 2015, 20, 287-293.

64. Soffritti, M.; Tibaldi, E.; Padovani, M.; Hoel, D.G.; Giuliani, L.; Bua, L.; Lauriola, M.; Falcioni, L.; Manservigi, M.; Manservisi, F.; Panzacchi, S.; Belpoggi, F. Life-span exposure to sinusoidal-50 Hz magnetic field and acute low-dose gamma radiation induce carcinogenic effects in Sprague-Dawley rats. Int J Radiat Biol 2016, 92, 202214.

65. International EMF Scientist Appeal. Available online: https://emfscientist.org/ (accessed on August 15, 2016).

(C) 2016 by the author; licensee Preprints, Basel, Switzerland. This article is an open access article distributed under the terms and conditions of the Creative Commons by Attribution (CC-BY) license (http://creativecommons.org/licenses/by/4.0/). 